\title{
Glutathione $S$-transferase M1 and GST T1 genetic polymorphisms and Raynaud's phenomenon in French vinyl chloride monomer-exposed workers
}

\author{
Luc Fontana • Marie-Jeanne Marion · \\ Sylvie Ughetto · Pierre Catilina
}

Received: 7 April 2006/ Accepted: 9 July 2006/ Published online: 15 September 2006

(C) The Japan Society of Human Genetics and Springer-Verlag 2006

\begin{abstract}
Occupational vinyl chloride monomer (VCM) exposure can induce Raynaud's phenomenon (RP). However, not all VCM workers developed RP, which suggests an underlying genetic susceptibility. Genetic polymorphisms of glutathione $S$-transferases (GSTs), involved in VCM metabolism, have been shown to influence certain VCM-related health effects. We have conducted a case-control study of 58 subjects with RP along with 247 subjects without RP, from a population of 305 French workers exposed or formerly exposed to VCM, to assess any association between GST M1 and GST T1 gene polymorphisms, either
\end{abstract}

\author{
L. Fontana $(\bowtie)$ \\ Institut de Médecine du Travail, Faculté de Médecine, \\ UFR Médecine, Univ Clermont 1, 28 place Henri Dunant, \\ 63001 Clermont-Ferrand, France \\ e-mail: Luc.FONTANA@u-clermont1.fr \\ L. Fontana \\ Service de Médecine du travail et de pathologie \\ professionnelle, CHU Clermont-Ferrand, \\ 28 place Henri Dunant, 63001 Clermont-Ferrand Cedex, \\ France \\ M.-J. Marion \\ INSERM U271, 151 cours Albert Thomas, \\ 69424 Lyon Cedex 03, France \\ S. Ughetto \\ Service d'épidémiologie, économie de santé et prévention, \\ CHU Clermont-Ferrand, Hôtel Dieu, \\ boulevard Léon Malfreyt, \\ 63000 Clermont-Ferrand, France \\ P. Catilina \\ Faculté de Médecine, Institut de Médecine du Travail, \\ Université d'Auvergne, 28 place Henri Dunant, \\ 63001 Clermont-Ferrand Cedex, France
}

separately or in combination, and the presence of RP. None of the GST M1 or GST T1 genotypes were significantly associated with the presence of RP among studied VCM workers. A combination of positive genotypes for both GST M1 and GST T1 was significantly associated with RP presence, compared to the other combinations of genotypes ( $\mathrm{OR}=2.1,95 \%$ $\mathrm{CI}=1.1-3.8$ ). OR adjusted for age, smoking status, alcohol consumption and history of treated hypertension did not reach significance $(\mathrm{OR}=2.0,95 \% \mathrm{CI}=0.9$ 5.2). None of the GST $M 1$ and GST T1 genotypes seem to contribute separately to the presence of RP, suggesting that they are not, when taken alone, a major determinant of interindividual variability for VCMinduced PR. However, the combination of both positive GST M1 and GST T1 genotypes appears to contribute slightly to susceptibility to RP in VCM-exposed subjects. Nevertheless, our study-the first to examine the role of a genetic component in the occurrence of RP secondary to occupational exposure to a chemical-corroborates the previous considerations that interaction between the genetic constitution and environmental factors is of importance in determining the health-adverse effects of VCM exposure.

Keywords Raynaud's phenomenon - Genetic polymorphism - Glutathione $S$-transferase M1 . Glutathione $S$-transferase T1 • Vinyl chloride . Occupational exposure

\section{Introduction}

Vinyl chloride monomer (VCM) (C.A.S. no. 75-01-4), a colourless gas under ambient conditions, is involved 
in the manufacture of polyvinyl chloride (PVC), a widely used plastic.

From the beginning of PVC production in the 1930s to the first regulations on the emission of $\mathrm{VCM}$ in the working environment in the 1970s, many workers in several countries were exposed by inhalation to high levels of VCM in polymerisation plants.

Exposure to VCM is associated with a multisystem disorder, called VCM disease, which may include hepatic, dermal, vascular, and neurological dysfunctions (Veltman et al. 1975; Suciu et al. 1975). VCM exposure is toxic for the vascular endothelium, as shown by angiographic studies of hand arteries and by capillaroscopic examinations (Falappa et al. 1982; Maricq et al. 1976). VCM exposure can induce Raynaud's phenomenon (RP), characterized by episodic digital vasospasm provoked mainly by cold (Wilson et al. 1967). The prevalence of RP in VCM workers ranges from 6 to 33\% (Veltman et al. 1975; Suciu et al. 1975; Wilson et al. 1967; Carpentier et al. 1985).

The first cases of RP were recorded in workers called autoclave cleaners, who were lowered into reactor vessels to clean polymer residues stuck to the walls manually; these were usually the highest VCMexposed jobs in PVC-polymerisation plants (Wilson 1967; Harris and Adams 1967; Veltman et al. 1975; Suciu et al. 1975; Maricq et al. 1976; Markowitz et al. 1977). However, other cases have since been described in VCM-exposed workers who had never been employed for this type of job or who had worked in less exposed workplaces (Black et al. 1986; Walker 1976; Freudiger et al. 1988).

In one of our previous studies, in a population of male, former VCM-exposed workers employed in the same VCM plant, which was a subset of a French cohort of VCM-exposed workers, we observed that only some workers $(9 \%)$ showed symptoms of RP, despite similar histories of high or long-term exposure and of presumably similar toxic insults (Fontana et al. 1995).

Thus, even if the prevalence of RP in the VCMexposed worker population is higher than that of primary RP observed in the general population (usually between 4 and $9 \%$ in women, and 3 and $6 \%$ in men), not all VCM workers, in particular those who had been exposed to high levels of VCM, developed clinical symptoms of RP.

This leads one to speculate that factors other than exposure levels play a part in the occurrence of observed RP. According to Black et al. (1986), acroosteolysis and RP are not only due to high exposure but idiosyncrasy seems to be an important factor too. They suggested that susceptibility to symptoms of "VC disease" is increased in the presence of human leuko- cyte antigen (HLA)-DR5 or of genes in linkage disequilibrium with it and an antigen associated with haplotype A1B8, while DR3 favours progression of the disease (Black et al 1986). However no further studies were identified that would confirm these results. Interindividual variation in the functional activity of metabolizing enzymes involved in VCM metabolism, such as glutathione $S$-transferases (GSTs), could be another reason.

The GST family is known to be involved in the metabolism of environmental chemical agents, including VCM, playing critical roles in protection against products of oxidative stress and electrophilic compounds (Ketterer 1988; Autrup 2000). Polymorphisms exist with regard to GST M1 and GST T1 genes, members of the $G S T$ supergene family, encoding for two classes of soluble GSTs: mu and theta. Genetic polymorphisms could in part explain interindividual variation in the GST activities. Carriers of GST M1 and GST $T 1$ homozygous inherited deletion genotypes lack the corresponding enzyme activities (Pemble et al. 1994).

Few human studies have been conducted on the association between $G S T$-gene polymorphisms and VCM-related health effects. Such studies have mainly concerned liver lesions and carcinogenic processes, with none conducted about RP (Huang et al. 1997; Wong et al. 1998, 2002; Li et al. 2005; Zhu et al. 2005).

For these reasons, the aim of this study was to investigate the association between GST M1 and GST $T 1$ genotype polymorphisms and the presence of RP secondary to occupational VCM exposure in a French population of VCM-exposed workers or former VCM workers.

\section{Materials and methods}

\section{Subjects and VCM exposure}

Subjects for study were volunteers from a previously described French cohort of VCM-exposed workers or former VCM workers (Smith et al. 1998). Studied subjects were all Caucasian males and had worked for at least 1 year in one of seven VCM-polymerisation or PVC-processing plants. All subjects agreed to written informed consent to participate. Two groups were distinguished: the cases were subjects exposed or formerly exposed to VCM, with RP secondary to VCM exposure $(n=58$; mean age $\pm \mathrm{SD}=65.9 \pm 7.9$ years; mean duration of employment $\pm \mathrm{SD}=24.2 \pm 8.6$ years) and the controls were subjects exposed or formerly exposed to VCM, without RP $(n=247$; mean 
age $\pm \mathrm{SD}=64.1 \pm 7.7$ years; mean duration of employment $\pm \mathrm{SD}=21.4 \pm 8.7$ years)

The diagnosis of RP was based on a history of blanching of the digits, or bi- or tri-phasic sequence of colour changes of the digits extended to at least the distal interphalangeal, involving thumbs. Diagnosis of RP secondary to VCM exposure was suggested on the basis of medical history and general physical examination of studied workers. Thus, none of cases showed clinical features suggesting other known causes of RP, such as rheumatic or systemic diseases, conditions causing large-artery diseases, or environmental injury, and, finally, for all cases, the onset of RP features occurred during the VCM-exposed period.

From the beginning of PVC production until the 1970s, exposure to VCM occurred by inhalation in VCM-polymerisation plants and PVC-processing plants. Ambient VCM in the working environment was emitted from the PVC-polymerisation process during opening of polymerisation tanks, PVC unloading, stripping, and drying. The PVC resin was processed by extrusion or calendering for the manufacture of PVC products such as pipes, and thick or thin films. The PVC resin contained significant amounts of residual VCM, which could be released during processing. From 1975 until now, the level of VCM tolerated at VCM and PVC workplaces has been maintained at very low levels in compliance with French and European recommendations.

Cases and controls were interviewed using a structured questionnaire identifying socio-demographic variables, including smoking habits and alcohol consumption, medication, and medical and detailed occupational histories.

\section{Identification of GST M1 and GST T1 genotypes}

Blood samples were obtained via venipuncture from each of 58 cases and 247 controls and were delivered within $24 \mathrm{~h}$ to be processed for the analysis of GST polymorphisms.

DNA was extracted from whole blood or lymphocytes using standard techniques. GST M1 and GST T1 genotypes were then determined by polymerase chain reaction (PCR) using primers and conditions as described by Zhong et al. (1993) and Pemble et al. (1994) respectively. Briefly, the PCR was carried out in an Applied Biosystems 2400 DNA thermal cycler (Apllera, Courtaboeuf, France) as follows: for GST M1 genotyping, samples were subjected to 30 cycles of denaturing $\left(94^{\circ} \mathrm{C}\right.$ for $\left.10 \mathrm{~s}\right)$, annealing $\left(52^{\circ} \mathrm{C}\right.$ for $\left.10 \mathrm{~s}\right)$, and extension $\left(72^{\circ} \mathrm{C}\right.$ for $\left.30 \mathrm{~s}\right)$, with an initial denaturation for $5 \mathrm{~min}$ at $94^{\circ} \mathrm{C}$ and a final extension at $72^{\circ} \mathrm{C}$ for $5 \mathrm{~min}$. For GST $T 1$ genotyping, samples were subjected to 30 cycles of denaturing $\left(94^{\circ} \mathrm{C}\right.$ for $\left.1 \mathrm{~min}\right)$, annealing $\left(66^{\circ} \mathrm{C}\right.$ for $\left.1 \mathrm{~min}\right)$, and extension $\left(72^{\circ} \mathrm{C}\right.$ for $1 \mathrm{~min}$ ), with an initial denaturation for $4 \mathrm{~min}$ at $94^{\circ} \mathrm{C}$ and a final extension for $5 \mathrm{~min}$ at $72^{\circ} \mathrm{C}$.

PCR products were separated on agarose NusieveGTG gel (FMC, Rockland, ME, USA) by electrophoresis, stained with ethidium bromide and visualised under ultraviolet light. The expected sizes of amplified products of GST M1, GST T1 and GST M4 (used as an internal control) were 230, 480 and 157 bp (base pairs) respectively (Zhong et al. 1993; Pemble et al. 1994). Homozygous null genotypes of GST M1 and GST T1 were determined by identifying the negative band for each size (with the simultaneous presence of the positive control); positive bands meant the sample was homo- or heterozygous for the indicated alleles. Two independent readers interpreted the results. Any sample with ambiguity was retested. No discrepancies were discovered upon replicate testing. The genotype with homozygous deletion of the GST genes is called "GST-null", whereas the genotype having at least one copy of the gene is called "GST-positive".

\section{Statistical analysis}

Because environmental monitoring data were not available before the discovery of the carcinogenic effects of VCM at the end of the 1970s, and for some plants until the 1980s, exposure had to be estimated. Cleaning of reactors, PVC slurry drying and PVC powder packing, maintenance, control and development laboratories were probably the highest VCMexposed jobs or environments. However, it was assumed that, during the same period, all workers were more or less exposed to the same level of VCM.

The VCM-exposure estimations used for the analysis were based on:

- Duration of employment in a VCM-plant, expressed as years

- Duration of employment before the year 1975, considered as highest-exposure period, expressed as years

- Cumulative VCM exposure, expressed as ppm (parts per million)-years. For the period before the year 1975, we used the estimated exposure levels of Heldaas et al. (1984). For the period from the year 1975, the cumulative exposure was based on recommended French VCM limit values.

Chi-square test, Fisher's exact test and student's $t$ test were used to compare the differences in basic characteristics between the group of subjects with RP 
and the group of subjects without RP. A $P$ value $<0.05$ was regarded as statistically significant. To assess the individual effect of potential risk factors on the presence of RP and to estimate crude odds ratio (OR), $G S T$ genotypes, combination of $G S T$ genotypes, and VCM-exposure level estimates (duration of employment, duration of employment before 1975, cumulative exposure) were included in the univariate analysis. To investigate the joint effect of VCM exposure and GST $M 1, G S T T 1$ genotypes, and the combinations of GST genotypes, stratified analyses by VCM-exposure levels (duration of employment, duration of employment before 1975, cumulative exposure) were used. Because of the small size of the case group, it was not possible to distinguish more than two exposure groups in the analysis. Thus, for each exposure estimation, two exposure categories were defined and the median of the distribution of the exposure variable among the 305 studied subjects as a cut-off point between lowest and highest exposures was used: 23 years for duration of employment, 17 years for duration of employment before 1975, and 7,700 ppm for cumulative exposure.

Subsequently, a multiple logistic regression model was used to estimate the effect on the adjusted ORs of the presence or absence of RP and of the above studied factors, genotypes of GST M1 and GST T1, combination of genotypes, VCM-exposure level estimations (duration of employment, duration of employment before 1975, cumulative exposure) and the effect of confounding factors. ORs were adjusted based on recognised risk factors for RP including age and smoking status. Although alcohol consumption did not turn out to be a significant RP risk, it was implemented into the model to allow a comparison with common VCM models used in literature (Huang et al. 1997; Wong RH et al. 2002). The model included history of treated hypertension because (1) the prevalence of condition was significantly different between the RP case group and the control group ( 22.3 vs. $11.4 \%)$, (2) hypertensive disease is a condition that may be associated with RP, and (3) certain antihypertensive drugs, such as beta-blockers, may induce RP (Grassi et al. 1998; Williams et al. 2004). The GST-null genotypes and the lowest VCM exposures were used as the reference categories for statistical analyses (Huang et al. 1997). Statistical analyses were performed using the PC Statistical Analysis System software (SAS Institute, Cary, NC, USA).

\section{Results}

The basic characteristics of the 305 studied VCM workers are summarized in Table 1 . The group of
VCM workers with RP had a statistically significant higher prevalence of history of hypertension compared to the group of VCM workers without RP (13/58 vs. 28/ 247). There was a statistically significant higher estimated VCM exposure among the group of VCM workers with RP compared to the group without RP, irrespective of the exposure estimation method adopted, i.e. duration of employment, duration of employment before 1975, and cumulative exposure. Otherwise none of the other characteristics were statistically different between these two groups, especially with regard to age.

The frequencies of positive genotypes (wild-type) of GST M1 and GST T1 in the total studied population $(n=305)$, were 37.7 and $80.7 \%$ respectively. These frequencies were 46.6 and $84.5 \%$, in the group with RP $(n=58)$, and, in the group without RP $(n=247), 35.6$ and $79.8 \%$.

The results of univariate analysis are shown in Table 2. None of the GST M1 or GST T1 genotypes were significantly associated with the presence of RP among studied VCM workers. The combination of positive genotypes for both GST M1 and GST T1 was significantly associated with RP presence, compared to the other combinations of genotypes $(\mathrm{OR}=2.1,95 \%$ $\mathrm{CI}=1.1-3.8)$. No other genotype combinations showed any significant combined effects on RP prevalence (data not shown). Using VCM exposure $<23$ years of duration of employment as a reference, the OR was

Table 1 Basic characteristics of 305 studied VCM workers stratified by presence of Raynaud's phenomenon $(R P)$

\begin{tabular}{lll}
\hline Characteristic & $\begin{array}{l}\text { Without RP } \\
(n=247)\end{array}$ & $\begin{array}{l}\text { With RP } \\
(n=58)\end{array}$ \\
\hline Age (years) & $64.1 \pm 7.7$ & $65.9 \pm 7.9$ \\
Obesity & $4(1.6)$ & $1(1.7)$ \\
Daily drinker & $56(22.6)$ & $17(29.3)$ \\
Current smoker & $52(21.1)$ & $9(15.5)$ \\
Former smoker & $89(36.1)$ & $24(41.4)$ \\
Non-smoker & $104(42.1)$ & $25(43.1)$ \\
Infarct history or & $22(8.9)$ & $3(5.2)$ \\
$\quad$ coronaropathy & $28(11.3)$ & $13(22.4)$ \\
Hypertension* & $9(3.6)$ & $2(3.4)$ \\
Arteritis & $6(2.4)$ & $0(0)$ \\
Cancer antecedents & $14(5.7)$ & $1(1.7)$ \\
Diabetes mellitus & $37(14.9)$ & $8(13.8)$ \\
Hyperlipidemia & $21.4 \pm 8.7$ & $24.2 \pm 8.6$ \\
Duration of employment* & & \\
$\quad$ years) & $16 \pm 7.2$ & $17.7 \pm 6.5$ \\
Duration of employment & & \\
$\quad<1975 *$ (years) & & \\
Cumulative exposure* (ppm) & $9,385.7 \pm 7,931.1$ & $11,208.7 \pm 7,698.5$ \\
\hline Values are either mean $\pm \mathrm{SD}$, or $n(\%)$ & \\
a Obesity=body mass index $>30 \mathrm{~kg} / \mathrm{m}^{2}$ & \\
$* P<0.5$ & &
\end{tabular}


Table 2 Influence of GST M1 and GST T1 genotypes and VCMexposure level estimates on Raynaud's phenomenon (RP) presence in $305 \mathrm{VCM}$-exposed subjects

\begin{tabular}{|c|c|c|c|}
\hline Variable & $\begin{array}{l}\text { Without RP } \\
(n=247) \\
{[n(\%)]}\end{array}$ & $\begin{array}{l}\text { With RP } \\
(n=58) \\
{[n(\%)]}\end{array}$ & $\begin{array}{l}\text { OR } \\
(95 \% \mathrm{CI})\end{array}$ \\
\hline \multicolumn{4}{|l|}{$G S T M 1$} \\
\hline Positive & $88(35.6)$ & $27(46.6)$ & 1.0 (reference) \\
\hline Null & $159(64.4)$ & $31(53.4)$ & $0.6(0.3-1.1)$ \\
\hline \multicolumn{4}{|l|}{$G S T T 1$} \\
\hline Positive & $197(79.8)$ & $49(84.5)$ & 1.0 (reference) \\
\hline Null & $50(20.2)$ & $9(15.5)$ & $0.7(0.3-1.6)$ \\
\hline \multicolumn{4}{|l|}{ GST M1/GST T1 } \\
\hline Other combination & $180(72.8)$ & $33(56.9)$ & 1.0 (reference) \\
\hline Positive/positive & $67(27.2)$ & $25(43.1)$ & $2.0(1.1-3.8)$ \\
\hline \multicolumn{4}{|c|}{ Employment duration } \\
\hline$<23$ years & $130(52.6)$ & $20(34.5)$ & 1.0 (reference) \\
\hline$\geq 23$ years & $117(47.4)$ & $38(65.5)$ & $2.1(1.1-3.8)$ \\
\hline \multicolumn{4}{|c|}{ Employment duration before 1975} \\
\hline$<17$ years & $119(48.2)$ & $22(37.9)$ & 1.0 (reference) \\
\hline$\geq 17$ years & $128(51.8)$ & $36(62.1)$ & $1.5(0.8-2.7)$ \\
\hline \multicolumn{4}{|c|}{ Cumulative exposure } \\
\hline$<7,700$ ppm-years & $130(52.6)$ & $22(37.9)$ & 1.0 (reference) \\
\hline$\geq 7,700$ ppm-years & $117(47.4)$ & $36(62.1)$ & $1.8(1.0-3.3)$ \\
\hline
\end{tabular}

ppm Parts per million, $O R(95 \% C I)$ odds ratio with $95 \%$ confidence interval

statistically significantly higher for individuals with estimated VCM exposure $\geq 23$ years $(2.11 ; 95 \%$ $\mathrm{CI}=1.16-3.83)$. Using the other estimations of exposure, duration of employment before 1975 and cumulative exposure, ORs were also higher for the workers subjected to a higher VCM exposure, but not significant.

Stratified analysis revealed that in the lowest VCMexposure group ( $<23$ years of duration of employment in VCM industries), the frequency of GST M1-positive genotype and the frequency of GST T1-positive genotype were higher in subjects with RP, compared with GST M1-null genotype $(1.4,95 \% \mathrm{CI}=0.5-3.5)$ and GST T1-null genotype $(2.4,95 \% \mathrm{CI}=0.5-10.8)$ respectively, used as the reference categories (data not shown). In the highest VCM-exposure group ( $\geq 23$ years of duration of employment in VCM industries), only the frequency of GST M1-positive genotype was not significantly higher in subject with RP, compared with GST M1-null genotype $(1.8,95 \% \mathrm{CI}=0.8$ 3.8 ), used as the reference category (data not shown). The frequency of positive genotypes for both GST M1 and GST T1 was higher in subjects with RP, compared to the other combinations of genotypes used as the reference categories, in the highest VCM-exposure group ( $\geq 23$ years of duration of employment in VCM- industries $)(\mathrm{OR}=2.10,95 \% \mathrm{CI} \sim 1.0-4.53)$ and in the lowest VCM-exposure group ( $<23$ years of duration of employment in VCM-industries $) \quad(\mathrm{OR}=2.0, \quad 95 \%$ $\mathrm{CI}=0.8-5.4$ ) (data not shown). However, all these results were not significant. Using the other estimations of exposure, duration of employment before 1975 and cumulative exposure, the results were similar and not significant.

Finally, multivariate analysis revealed exposure-level expressed as duration of employment in VCM industries ( $<23$ vs. $\geq 23$ years), independently of $G S T$ $M 1$ and GST T1 genotypes, to be associated with an increased $\mathrm{OR}$ for $\mathrm{RP}(\mathrm{OR}=2.1,95 \% \mathrm{CI}=1.1-3.8)$ (data not shown). Combination of positive genotypes for both $G S T M 1$ and $G S T T 1$ was associated with RP presence but adjusted OR did not reach significance (OR=2.0, 95\% CI=0.9-5.2) (data not shown).

\section{Discussion}

First of all, in our series, frequencies of GST M1 deletions of $62.3 \%$ and of GST T1 deletions of $19.3 \%$ in all populations, and of 64.4 and of $20.2 \%$ respectively in the control group, are close to (slightly higher than) those found in a French population including male and female subjects: $53.4 \%$ for GST M1 ( $n=1,184), 16.8 \%$ for GST T1 ( $n=512)$; and those found in a male Caucasian population, $52.6 \%$ for GST M1 $(n=6,015)$ and $18.1 \%$ for GST T1 $(n=3,181)$ (Garte et al. 2001). These findings, to some extent, validate the technique of our genotyping.

In this study, we attempted to determine whether or not polymorphisms of GST M1 and GST T1 may be a reason for genetic susceptibility to secondary RP with VCM exposure.

In the univariate analysis, no studied GST genotype was found to have a statistically significant effect on RP status among VCM workers. Because the metabolism of VCM may differ at different concentrations, stratified analysis was then used to explore the association between the presence of RP and the genotypes among the VCM workers exposed to different levels of VCM. Indeed, in animals, at low levels of exposure, VCM is metabolized in the liver by alcohol dehydrogenase (ALDH2) to form mainly monochloroacetic acid, which is excreted in the urine, and two highly reactive metabolites: chloroethylene oxide (CEO) and chloroacethaldehyde (CAA) (Tamburro 1984; Guengurich et al. 1981). At higher exposures, VCM is transformed by the cytochrome P450 2E1 (CYP 2E1) into CEO and CAA (Tamburro 1984; Guengurich et al. 1981). These two compounds are detoxified 
mainly through glutathione (GSH) conjugation directly or enzymatically via GSTs, resulting in the excretion of urinary metabolites (Lewis 1999; Tamburro 1984). Finally, VCM may be directly metabolized by GSTs to conjugate with GSH (Hefner 1975).

In humans, Huang et al. (1997) observed that the OR for Taiwanese individuals with positive GST T1 occupationally exposed to a high level of VCM on abnormal alanine aminotransferase (ALA) was 0.6 times that of individuals with null GST $T 1$ at low exposures. The OR for individuals with positive GST $T 1$ at lower exposures on abnormal ALA was 7.1 times higher than individuals with null GST $T 1$ at lower exposure (Huang et al. 1997). No association was found with GST M1 genotypes (Huang et al. 1997). The same researchers reported later that, in the lowexposure group, non-null GST $T 1$ was associated with an increased risk of p53 overexpression compared with null GST T1 (Wong et al. 2002). In the high-exposure group, p53 overexpression did not differ between nonnull and null genotypes, although they had a higher risk of p53 overexpression as compared with GST T1 null in the low-exposure group (Wong et al. 2002). For these authors, the possible explanation is the limited capacity of VCM metabolism through GST T1 (Wong et al. 2002), and they suggest that VCM may mainly be metabolized directly by GST T1 at low concentrations (Wong et al. 2002). Our stratified analysis on exposure showed that GST T1 positive genotype frequency was higher in VCM workers with RP at lowest exposures, and GST M1 positive genotype frequency was higher in VCM workers with RP at lowest exposures. However, these results were not significant.

Thus, GST M1 and GST T1 polymorphisms do not seem to contribute separately to the presence of secondary RP with VCM exposure. Other enzymatic systems are involved in the metabolism and toxicity of VCM, and they could have a more important role or interact with each other, masking the individual effect of GSTs or influencing the impact of their activity. A previous analysis of another sample from the same French cohort of VCM workers, exposed to VCM in similar conditions, focused on the modifying role of polymorphic GST M1, GST T1 and GST P1 on the occurrence of mutant p53 biomarkers of VCM-induced genetic damage (Li et al. 2005). GST M1-null and GST T1-null genotypes were found to have a number of nonsignificant effects, whereas they significantly interacted with DNA repair protein genotypes (X-ray crosscomplementing-1 protein, $X R C C 1)$ to increase the occurrence of the biomarker (Li et al. 2005).

The main significant finding of our study was that the frequency of positive GST M1 and GST T1 geno- types together was higher in VCM workers with RP compared with VCM workers without RP. However, after controlling for other sources of variability, this association did not reach significance in the multivariate analysis. The role of GST enzymes in VCM metabolism, protective or not, remains controversial, and as noted above, may depend on VCM concentrations. Protective roles have been described in animal studies (Tamburro 1984; Guengurich et al. 1981). In humans, Huang et al. (1997) observed a protective role for Taiwanese individuals with positive GST T1 who were occupationally exposed to a high level of VCM. Recently, a study on the relationship between liver lesions and gene polymorphisms of metabolic enzymes in Chinese VCM-exposed workers showed that GST $T 1$ non-null genotype protected the workers from exposure to low levels of VCM (Zhu et al. 2005).

On the other hand, Wong et al. $(1998,2002)$ suggested that GST T1, at low exposure, may be involved in VCM activation to form toxic intermediates, demonstrating a substantial mutagenic activity and hepatotoxicity (Wong et al. 1998, 2002).

Moreover, GSH conjugates, produced directly or after catalysis by GSTs, have been suggested to contribute to activation and then to toxicity of some chemicals (Hefner et al. 1975). In an experimental study, the GSH conjugation of dihalomethanes, such as dichloromethane, which have a similar chemical structure to VCM, has been clearly demonstrated to result in genotoxicity (Thier et al. 1993). Garnier et al. (1996) reported, after acute inhalation exposure to methyl bromide involving two workers, the GST T1positive worker showed signs of severe neurotoxicity, whereas the second worker, with GST T1-null genotype, developed only mild neurotoxic symptoms. The activation of methyl bromide to methylglutathione and thereafter to neurotoxic metabolites was suggested as occurring only in the GST T1-positive subject (Garnier et al. 1996). Finally, individuals with genotypes positive for both GST T1 and GST M1 showed the highest prevalence of low white blood cells when estimated occupational benzene exposure was high (Hsieh et al. 1999).

There are probably important differences between the classes of GSTs in localisations, in catalytic activities due, for example, to the substrate specificity, chemical affinity or structure, which might explain differences in activity, leading to different clinical or biological features.

Our results indicate that GST T1 and GST M1 might work together with subsequent increased production of conjugated compounds, and the biological plausibility would involve a vulnerability of vascular endothelium 
to the toxic effects of GSH-conjugated intermediates. It is well known that arsenic exposure also leads to a variety of vascular diseases, including RP. Recently, Hirano et al. suggested that glutathione conjugates of arsenic are toxic in rat heart micro-vessel endothelial cells (Hirano et al. 2004). In many studies, endothelial damage has probably occurred because several studies have documented vascular injury and microvascular lesions in CVM disease (Suciu et al. 1975; Fallappa et al. 1982; Maricq et al. 1976; Freudiger et al. 1988). However, to date, no experimental endothelial toxicity of any VCM metabolites, whether conjugated or not, has been documented.

To the best of our knowledge, there have been few genetic investigations into primary or secondary RP. RP is commonly observed in connective tissue diseases. Some of them are known to occur in genetically susceptible patients, mainly linked to human leukocyte antigen (HLA), influenced by environmental factors (Uhm et al. 2002). However, the precise genetic factors that could affect the presence of RP in these diseases have not yet been identified. A genetic susceptibility in primary RP has been suggested, based mainly on family aggregation observations and on results providing evidence of the presence of genes that are involved in susceptibility to primary RP (Susol et al. 2000). However, it is unknown whether primary RP is a monogenic or an oligogenic disease and whether the genetic basis varies among individuals (Susol et al. 2000). Recently, a twin study identified phenotypic associations among four conditions characterised by blood vessel occlusion or vascular spasm, including hypertension, Raynaud's phenomenon, migraine and coronary artery disease (Williams et al. 2004). It showed that the association is explained by a single common genetic factor (Williams et al. 2004). However, according to the authors, the difficulty is in establishing which genes are responsible (Williams et al. 2004). Finally, Miller et al. (2003) provided some limited evidence that GST M1 and GST T1 polymorphisms modify the effect of smoking on some markers of endothelial function. To our knowledge, our study is the first to examine the role of a genetic component in the occurrence of RP secondary to occupational exposure to a chemical and to evoke a possible gene-environment interaction.

In conclusion, our results tend to indicate that GST M1 and GST T1 genotypes are not, when taken alone, a major genetic determinant of interindividual variability for VCM-induced RP. However, the combination of both positive GST M1 and GST T1 genotypes appears to contribute slightly to susceptibility to RP in VCM-exposed subjects. This finding is intriguing but, because it is based on a relatively small number of RP cases and since no previous studies on the potential role of VCM-metabolism enzyme genetic polymorphisms in the development of RP among VCM workers have been published, this result should be considered with caution until it is confirmed in future studies. Nevertheless our findings corroborate the previous considerations that interaction between genetic constitution and environmental factors is of importance in determining the health-adverse effects of VCM exposure.

Acknowledgements We thank Ms Lydie Lefrançois for her excellent technical assistance.

\section{References}

Autrup H (2000) Genetic polymorphisms in human xenobiotoca metabolizing enzymes as susceptibility factors in toxic response. Mutat Res 464:65-76

Black C, Pereira S, Mac Whirter A, Welsh K, Laurent R (1986) Genetic susceptibility to sclerodermalike syndrome on symptomatic and asymptomatic workers exposed to vinyl chloride. J Rheumatol 13:1059-1062

Falappa P, Magnavita N, Bergamaschi A, Colavati N (1982) Angiographic study of digital arteries in workers exposed to vinyl chloride. Br J Ind Med 39:169-72

Fontana L, Baietto M, Becker F, Catilina P (1995) Etude clinique et capillaroscopique de phénomènes de Raynaud chez des retraités anciennement exposés au chlorure de vinyle monomère [Clinical and capillaroscopic assessment of Raynaud's phenomenon in retired patients previously exposed to vinyl chloride monomer]. J Mal Vasc 20:268-273

Freudiger H, Bounameaux H, Garcia J (1988) Acro-osteolysis and Raynaud's phenomenon after vinyl chloride exposure. VASA 17:216-218

Garnier R, Rambourg-Schepens MO, Müller A, Hallier E (1996) Glutathione transferase activity and formation of macromolecular adducts in two cases of acute methyl bromide poisoning. Occup Environ Med 53:211-215

Garte S, Gaspari L, Alexandrie AK, Ambrosone C, Autrup JL, Baranova $\mathrm{H}$, Bathum L, Benhamou S, Boffetta $\mathrm{P}$, Bouchardy C, Breskvar K, Brockmoller J, Cascorbi I, Clapper ML, Coutelle C, Dally A, Dell'Omo M, Dolzan V, Dresler CM, Fryer A, Haugen A, Hein DW, Hildesheim A, Hirvonen A, Hsieh LL, Ingelman-Sundberg M, Kalina I, Kang D, Kihara M, Kiyohara C, Kremers P, Lazarus P, Le Marchand L, Lechner MC, Van Lieshout EM, London S, Manni JJ, Maugard CM, Morita S, Nazar-Stewart V, Noda K, Oda Y, Parl FF, Pastorelli R, Persson I, Peters WH, Rannug A, Rebbeck T, Risch A, Roelandt A, Romkes M, Ryberg D, Salagovic J, Schket B, Seidegard J, Shields PG, Sim E, Sinnet D, Strange RC, Stucker I, Sugimura H, ToFigueras J, Vineis P, Yu MC, Taioli E (2001) Metabolic gene polymorphism frequencies in control populations. Cancer Epidemiol Biomarkers Prev 10:1239-1248

Guengurich F, Mason P, Stott W, Fox TR, Watanabe PG (1981) Roles of 2-haloethylene oxides and 2-haloacethaldehyde derived from vinyl bromide and vinyl chloride in irreversible binding to protein and DNA. Cancer Res 41:1013-7

Grassi W, De Angelis R, Lapadula G, Leardini G, Scarpa R (1998) Clinical diagnosis found in patients with Raynaud's phenomenon: a multicentre study. Rheumatol Int 18:17-20 
Harris DK, Adams WGF (1967) Acro-osteolysis occurring in men engaged in the polymerisation of vinyl chloride. $\mathrm{Br}$ Med J 3:712-714

Hefner RE, Watanabe PGJ, Gehring PJ (1975) Preliminary studies of the fate of inhaled vinyl chloride monomers in rats. Ann NY Acad Sci 246:135-148

Heldaas SS, Langard SL, Andersen A (1984) Incidence of cancer among vinyl chloride and polyvinyl chloride workers. Br J Ind Med 41:25-30

Hirano S, Kobayashi Y, Cui X, Kanno S, Hayakawa T, Shraim A (2004) The accumulation and toxicity of methylated arsenicals in endothelial cells: important roles of thiol compounds. Toxicol Appl Pharmacol 198:458-467

Hsieh LL, Liou SH, Chiu LL, Chen YH (1999) Glutathione $S$ transferase (GST) M1 and GST T1 genotypes and hematopoietic effects of benzene exposure. Arch Toxicol 73:80-82

Huang CY, Huang KL, Cheng TJ, Wang JD, Hsieh LL (1997) The GST T1 and CYP2E1 genotypes are possible factors causing vinyl chloride induced abnormal liver function. Arch Toxicol 71:482-488

Ketterer B (1988) Protective role of glutathione and glutathione transferases in mutagenesis and carcinogenesis. Mutat Res 202:343-361

Lewis R (1999) Vinyl chloride and polyvinyl chloride. Occup Med 14:719-41

Li Y, Zhou M, Marion MJ, Lee S, Brandt-Rauf PW (2005) Polymorphims in glutathione $S$-transferases in French vinyl chloride workers. Biomarkers 10:72-79

Maricq HR, Johnson MN, Whetstone CL, Leroy EC (1976) Capillary abnormalities in polyvinyl chloride production workers. JAMA 236:1368-1371

Markowitz SS, MacDonald J, Fethiere W, Kerzner MS (1977) Occupational acro-osteolysis. Arch Dem 106:219-223

Miller EA, Pankow JS, Millikan RC, Bray MS, Ballantyne CM, Bell DA, Heiss G, Li R (2003) Glutathione-S-transferase genotypes, smoking, and their association with markers of inflammation, hemostasis, and endothelial function: the Atherosclerosis in Communities (ARIC) study. Atherosclerosis 171:265-272

Pemble S, Schroeder KR, Spenser SR, Meyer E, Hallier E, Bolt HM, Ketterer B, Taylor JB (1994) Human glutathione- $S$ transferase theta (GSTT1): cDNA cloning and the characterization of a genetic polymorphism Biochem J 300:271276

Smith SJ, Li Y, Whitley R, Marion MJ, Partilo S, Carney WP, Brandt-Rauf PW (1998) Molecular epidemiology of p53 protein mutations in workers exposed to vinyl chloride. Am J Epidemiol 147:302-308
Suciu I, Prodan L, Ilea F (1975) Clinical manifestations in vinyl chloride poisoning. Ann NY Acad Sci 246:53-69

Susol E, Mac Gregor AJ, Barett JH, Wilson H, Black C, Welsh K, Silman A, Ollier B, Worthington J (2000) A two-stage, genome-wide screen for susceptibility loci in primary Raynaud's phenomenon. Arthritis Rheum 43:1641-1646

Tamburro C (1984) Relationship of vinyl monomers and liver cancers: angiosarcoma and hepatocellular carcinoma. Semin Liver Dis 4:158-169

Thier R, Taylor JB, Pemble SE, Humphreys WG, Persmark M, Ketterer B, Guenguerich FP (1993) Expression of mammalian glutathione $S$-transferase 5-5 in Salmonella typhimurium TA 1535 leads to base-pair mutations upon exposure to dihalomethanes. Proc Natl Acad Sci USA 90:8576-8580

Uhm WS, Lee HS, Chunag YH, Kim TH, Bae SC, Joo KB, Kim TY Yoo DH (2002) Angiotensin-converting enzyme gene polymorphism and vascular manifestations in Korean patients with SLE. Lupus 11:227-233

Veltman G, Lange CE, Juhe S, Stein G, Blahner U (1975) Clinical manifestations and course of vinyl chloride disease. Ann NY Acad Sci 246:6-17

Walker AE (1976) Clinical aspects of vinyl chloride disease: skin. Proc R Soc Med 69:286-289

Williams FMK, Cherkas LF, Spector TD, McGregor AJ (2004) A common genetic factor underlies hypertension and other cardiovascular disorders. BMC Cardiovasc Disord 4:20

Wilson RH, MacCormick WE, Tatum CF (1967) Occupational acro-osteolysis: report of 31 cases. JAMA 201:557-581

Wong RH, Wang JD, Hsieh LL, Du CL, Cheng TJ (1998) Effect on sister chromatid exchange frequency of aldehyde dehydrogenase 2 genotype and smoking in vinyl chloride workers. Mutat Res 420:99-107

Wong RH, Du CL, Wang JD, Chan CC, Luo JCJ, Cheng TJ (2002) XRCC1 and CYP2E1 polymorphisms as susceptibility factors of plasma mutant p53 protein and anti-p53 antibody expression in vinyl chloride monomer-exposed polyvinyl chloride workers. Cancer Epidemiol Biomarkers Prev 11:475-482

Zhong S, Wyllie AH, Barnes D, Wolf CR, Spurr NK (1993) Relationship between the GSTM1 genetic polymorphism and susceptibility to bladder, breast and colon cancer. Carcinogenesis 14:1821-1824

Zhu SM, Ren XF, Wan JX, Xia ZL (2005) Evaluation in vinyl chloride monomer-exposed workers and the relationship between liver lesions and gene polymorphisms of metabolic enzymes. World J Gastroenterol 11(37):5821-5827 